\title{
Correlation of photoluminescent quantum efficiency and device characteristics for the soluble electrophosphorescent light emitter with interfacial layers
}

\author{
Nam Su Kang, ${ }^{1}$ Byeong-Kwon Ju, ${ }^{1}$ Ji Whan Kim, ${ }^{2}$ Jang-Joo Kim, ${ }^{2}$ Jae-Woong $\mathrm{Yu},{ }^{3}$ and \\ Byung Doo Chin 3 ,a) \\ ${ }^{1}$ Display and Nanosystem Laboratory, College of Engineering, Korea University, Seoul 136-713, \\ Republic of Korea \\ ${ }^{2}$ Department of Materials Science and Engineering and OLED Center, Seoul National University, \\ Seoul 151-744, Republic of Korea \\ ${ }^{3}$ Materials Science and Engineering Research Division, Korea Institute of Science and Technology, \\ P.O. Box 131, Cheongryang, Seoul 130-650, Republic of Korea
}

(Received 6 January 2008; accepted 26 May 2008; published online 25 July 2008)

\begin{abstract}
We have investigated the effects of interfacial layers on the properties of soluble phosphorescent organic light emitting devices. Two kinds of polyfluorene-based interfacial layer materials have been studied; both were spin coated on top of PEDOT:PSS to form the insoluble layers by thermal annealing. The molecular-doped, phosphorescent light emitting layer comprising a polymeric host, small molecular host, and guest molecule was fabricated onto the thin interfacial layer. The photoluminescence quantum yield (PLQY) of these layers was measured with an integrating sphere. We have calculated the PLQY values of the single phosphorescent light emitting layer and various organic multilayers incorporating the interfacial layers, showing that a reduction in PLQY due to the interfacial quenching is more significant in the thicker interfacial layer structures. In spite of the decrease in PLQY induced by the triplet energy mismatch, polyfluorene-based interfacial layers improved the charge injection from PEDOT:PSS to the emitting layer, which results in the enhanced brightness and current. The triplet quenching by the interfacial layer could explain the reduction in luminous efficiency of the devices compared to the reference. This was also investigated by studying the charge carrier trapping, change in the spectral characteristics induced by the shift in the emission zone, and the analysis on the carrier balance of devices. (C) 2008 American Institute of Physics.
\end{abstract}

[DOI: $10.1063 / 1.2959817$ ]

\section{INTRODUCTION}

Electrophosphorescent organic light emitting devices (OLEDs) have attracted considerable attention as potential candidates for full color display and solid-state lighting applications due to their high efficiency (internal quantum efficiency is nearly unity). ${ }^{1,2}$ Using dispersed phosphorescent dyes as the emitter in a matrix of polymeric materials (or blends of small molecular species), solution-processed phosphorescent devices have been widely investigated. ${ }^{3-7}$ For both thermally evaporated and solution-processed phosphorescent OLEDs, tailoring the device structures to balance the charge and to confine triplet excitons is a promising way to maximize efficiency and lifetime. For instances, graded doping profile, ${ }^{8}$ engineering at charge-blocking layers to confine exciton, ${ }^{9,10}$ and the concept of interfacial layer especially in the case of the soluble emitter ${ }^{11,12}$ are all useful methods for balancing charges and improving device properties. Recently, by utilizing the hole transport and light emitting layer with cross-linkable small molecular elements (oxatene reactive units), a multilayer-structured soluble phosphorescent

\footnotetext{
${ }^{a)}$ Author to whom correspondence should be addressed. Electronic mail: bdchin@kist.re.kr.
}

OLED with controllable thickness and higher efficiency was reported, ${ }^{13,14}$ showing efficiencies up to $58 \mathrm{~lm} / \mathrm{W}$ (lumen/W) of green emission.

It is well known that the interfacial layer inserted between the (3,4-ethylenedioxythiophene): poly(4-styrenesulfonate) (PEDOT:PSS) hole injection layer and light emitting polymeric layer significantly improves the device efficiency and lifetime in polymer OLEDs. This process is easy and compatible for large area device fabrication, although the detailed mechanism is somewhat unclear. Typical examples were hole-transporting materials such as $\quad \operatorname{poly}\left(9,9^{\prime}\right.$-dioctylfluorene-co- $N$-(4-butylphenyl) diphenylamine $)^{11,15}$ (TFB) and 4,4-bis[( $p$ - trichlorosilylpropylphenyl)phenylamino] biphenyl (TPDSi 2 ). ${ }^{16}$ In the case of soluble phosphorescent polymeric (or blends with small molecules) emitters that use fac-tris(2-phenylpyridine) iridium(III) $\left[\operatorname{Ir}(\mathrm{ppy})_{3}\right]$ as phosphorescent dopant, the triplet energy of TFB and other polyfluorene copolymers used as interlayers is lower than that of $\operatorname{Ir}(\mathrm{ppy})_{3}{ }^{17}$ Therefore, in most instances, the polymer phosphorescence can be quenched at the interface between the polyfluorene-based interfacial layer and the light emitting layer. Mixing of host compounds such as $\quad N, N^{\prime}$-diphenyl- $N, N^{\prime}$-(bis(3-methylphenyl)[1,1-biphenyl $] 4,4^{\prime}$-diamine (TPD) in the light emitting layer further facilitates the injection of holes to propagate into the emitting layer, far away from its interface with PEDOT:PSS 
or TFB. ${ }^{11}$ The improved efficiency of the interfacial-layeraided soluble phosphorescent devices can be explained by the assisted hole injection by use of a TPD cohost. Meanwhile, in the case of bis(1phenylisoquinoline)iridium(acetylacetonate) $\left[(\mathrm{piq})_{2} \operatorname{Ir}(\mathrm{acac})\right]$ red emitter/interfacial layer, the phosphorescent quenching at the interface is not significant. ${ }^{12}$ Therefore, to fabricate solution-processed devices with green (and certainly blue) phosphorescent molecular-doped emitters, investigations into the light emitting mechanism [for both photoluminescent (PL) and electroluminescent (EL) processes] focusing on the interfacial emission and quenching phenomena is extremely important.

A novel procedure to measure the photoluminescent quantum yield (PLQY) of an organic thin film (single layer) was reported by de Mello et al., ${ }^{18}$ which uses an integrating sphere. With their model [see Fig. 1 for the original equations; (a) laser beam irradiated for empty sphere, (b) laser beam directly irradiated the wall and scattered beam (with a fraction $\mu$ ) irradiated the sample, and (c) sample was directly irradiated by the laser beam], the absorption coefficient was determined via experiments on measuring the reflection and transmission. The area under the photoemission of the sample and laser incident profile is integrated to calculate the amount of emitted light $(P)$ and unabsorbed light $(L)$, respectively. ${ }^{18}$

In this paper, we investigated the light emitting (PL and EL) mechanism of interfacial-layer-aided soluble phosphorescent devices. Two interfacial layer materials, TFB and $\quad \operatorname{poly}\left(9,9^{\prime}\right.$-dioctylfluorene-co-bis- $N, N^{\prime}$-(4ethoxycarbonylphenyl)-bis- $N, N^{\prime}$-phenyl-benzidine (BFEC), were selected for comparing the PLQY and EL efficiencies. Assuming the same thickness of the light emitting layer, the method of calculating the PLQY using measurements via an integrating sphere was modified for a multilayered sample (using a spin-coated light emitting layer on top of the interfacial layers and PEDOT:PSS; different types and thicknesses). We have analyzed the PLQY results in correlation with the EL data of various OLED devices having the corresponding interfacial layer structure. The highest occupied molecular orbital (HOMO) and lowest unoccupied molecular orbital (LUMO) energy levels of the host, dopant, and interfacial layer were determined for the analysis of the electrical properties and injection of charge at the specific interfaces. Moreover, a precise shifting in the recombination zone that can be characterized in the EL spectral behavior was illustrated for different conditions of the interfacial layers. Our conclusions differ from those in other reported work on the effect of interfacial layers; there appears to be competition between the charge transport and quenching properties due to the use of the interfacial layer in molecularly doped phosphorescent devices.

\section{EXPERIMENT}

PEDOT:PSS (Baytron P TP AI4083, H.C. Starck) was used after being passed through a $0.45 \mu \mathrm{m}$ polytetrafluoroethylene filter. TFB and BFEC were dissolved in toluene $(0.07 \mathrm{mg} / \mathrm{ml})$ and filtered with a $0.2 \mu \mathrm{m}$ PTFE filter. A phos-

$L_{(b)}=L_{(a)}(1-\mu)$
$L_{(c)}=L_{(a)}(1-A)(1-\mu)$
$A=\left(1-\frac{L_{(c)}}{L_{(b)}}\right)$
$L_{(c)}+P_{\langle c)}=(1-A)\left(L_{\langle b\rangle}+P_{(b)}\right)+\eta L_{\langle a\rangle} A$
$\eta=\frac{P_{(c)}-(1-A) P_{(b)}}{L_{(a)} A}$

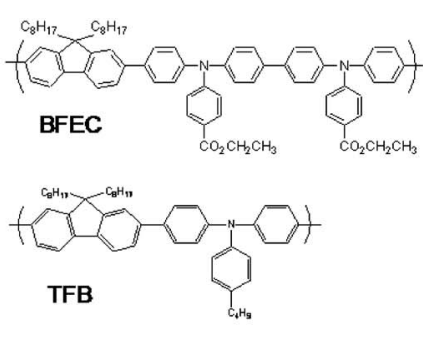

(i) Interfacial layers

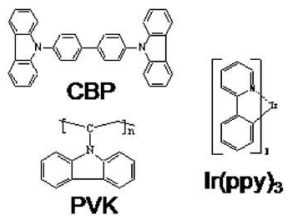

(b)

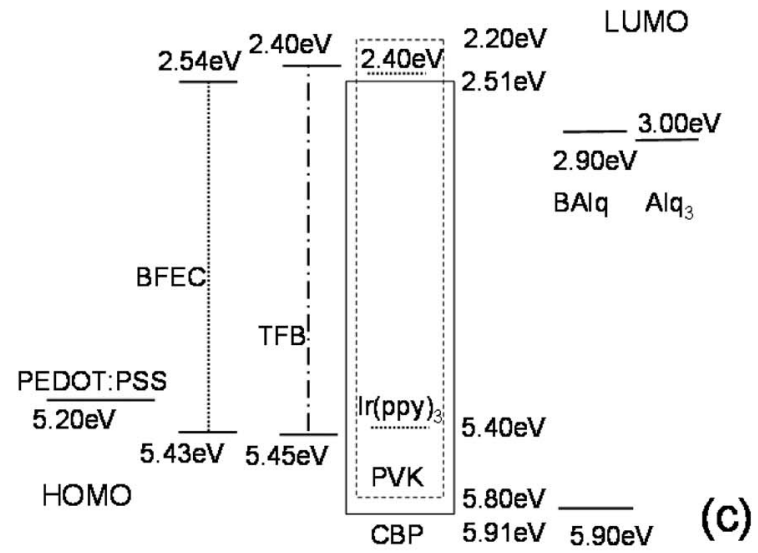

FIG. 1. (a) Original equation by de Mello et al. (Ref. 18). (b) Materials employed in this paper. (c) HOMO/LUMO energy level diagram of each layer in device using the interfacial layers and soluble phosphorescent emitter.

phorescent light emitting layer was composed of $4,4^{\prime}-N, N^{\prime}$-dicarbazole-biphenyl (CBP) as host, poly (9-vinyl carbazole) (PVK) as cohost and matrix, and $\operatorname{Ir}(\mathrm{ppy})_{3}$ as dopant with mixing ratio of 47.5:47.5:5 (in toluene solution).

The light emitting/interfacial double layer was prepared by spin coating a phosphorescent light emitting layer onto the thermally treated BFEC or TFB. After thermal annealing at $250{ }^{\circ} \mathrm{C}$ on a hot plate for $10 \mathrm{~min}$ in a nitrogen atmosphere, the residual of BFEC or TFB that was not cured was removed via spin rinsing with toluene for $60 \mathrm{~s}$. Since the thickness of the interfacial layer was hard to measure by conventional profilometry, the thicknesses of the interfacial layers (BFEC and TFB) were measured by the following method. The actual thickness of the double layer (interfacial layer/ light emitting layer) and the single light emitting layer (46 nm) was measured. Then the thicknesses of the BFEC and 
TABLE I. Sample code and layered structures of the films for PLQY measurements.

\begin{tabular}{|c|c|c|c|c|}
\hline Sample code & First layer & Second layer & Third layer & $\begin{array}{l}\text { Treatment of interfacial layer } \\
\text { (second layer) }\end{array}$ \\
\hline 1 & Quartz & & & \\
\hline 2 & CBP:PVK: $\operatorname{Ir}(\text { ppy })_{3}$ & & & \\
\hline 3 & PEDOT:PSS & & & \\
\hline 4 & PEDOT:PSS & CBP:PVK: $\operatorname{Ir}(\mathrm{ppy})_{3}(46 \mathrm{~nm})$ & & \\
\hline 5 & PEDOT:PSS & BFEC $(25 \mathrm{~nm})$ & & Annealing at $250{ }^{\circ} \mathrm{C}$ \\
\hline 6 & PEDOT:PSS & TFB $(16 \mathrm{~nm})$ & & Annealing at $250{ }^{\circ} \mathrm{C}$ \\
\hline 7 & PEDOT:PSS & BFEC (25 nm) & CBP:PVK: $\operatorname{Ir}(\mathrm{ppy})_{3}(46 \mathrm{~nm})$ & Annealing at $250{ }^{\circ} \mathrm{C}$ \\
\hline 8 & PEDOT:PSS & TFB $(16 \mathrm{~nm})$ & CBP:PVK: $\operatorname{Ir}(\mathrm{ppy})_{3}(46 \mathrm{~nm})$ & Annealing at $250{ }^{\circ} \mathrm{C}$ \\
\hline 9 & PEDOT:PSS & BFEC $(15 \mathrm{~nm})$ & CBP:PVK: $\operatorname{Ir}(\mathrm{ppy})_{3}(46 \mathrm{~nm})$ & Annealing at $250{ }^{\circ} \mathrm{C} /$ rinsing with toluene \\
\hline$\# 10$ & PEDOT:PSS & TFB $(15 \mathrm{~nm})$ & CBP:PVK: $\operatorname{Ir}(\mathrm{ppy})_{3}(46 \mathrm{~nm})$ & Annealing at $250{ }^{\circ} \mathrm{C} /$ rinsing with toluene \\
\hline
\end{tabular}

TFB portions were obtained from the difference between them. In the case of BFEC, we have observed a reduction in the thickness of the interfacial layer upon rinsing, whereas the TFB interfacial layer did not undergo a noticeable change in thickness. Table I shows the details of single- and multilayered samples for the measurement of PLQY including the thicknesses and structures, which were fabricated onto quartz substrates.

The patterned indium tin oxide $\left(4.0 \mathrm{~mm}^{2}\right.$ and $180 \mathrm{~nm}$ thick) substrates with a sheet resistance of $15 \Omega / \mathrm{sq}$ were used for device preparation. The substrates were cleaned with ultrasonication in de-ionized water and isopropanol alcohol several times and subjected to $\mathrm{UV}-\mathrm{O}_{3}$ treatment for 15 min. A $35 \mathrm{~nm}$ thick layer of PEDOT:PSS was spin coated on the substrates, followed by drying at $200{ }^{\circ} \mathrm{C}$ for $5 \mathrm{~min}$ on a hot plate. The procedure of annealing the BFEC/TFB on top of prebaked PEDOT:PSS at $250{ }^{\circ} \mathrm{C}$ yields layers that are partially insoluble upon successive spin coating of a $46 \mathrm{~nm}$ thick phosphorescent emitting layer, where the thickness of the BFEC interfacial layer was reduced in the spin-rinsing process. These samples were annealed again at $80{ }^{\circ} \mathrm{C}$ on a hot plate for $30 \mathrm{~min}$ in a nitrogen atmosphere. To complete the fabrication of an OLED device, a $5 \mathrm{~nm}$ thick hole blocking layer of aluminum(III) bis(2-methyl-8-quinolinato)4phenylphenolate (BAlq) was deposited as a hole blocking layer, followed by the deposition of a $25 \mathrm{~nm}$ thick electron transport layer of tris(8-hydroxyquinoline)-aluminum $\left(\mathrm{Alq}_{3}\right)$ and LiF/aluminum cathode layer via thermal evaporation at a vacuum level of $2 \times 10^{-7}$ Torr. For a direct comparison of the solution-processed and thermally evaporated light emitter on top of the interfacial layer, we have fabricated corresponding series of devices using CBP: $\operatorname{Ir}(\mathrm{ppy})_{3}$ evaporated emitters $(30 \mathrm{~nm})$ on the PEDOT:PSS and interfacial layers. The materials and the energy level diagram of the devices used in this study are shown in Fig. 1. Details of the fabricated layers and device structures are summarized in Table II, where the device codes are matched to the corresponding sample codes for PLQY measurements.

The experimental procedure and apparatus for the measurement of PLQY closely follow the ones described by de Mello et al. ${ }^{18}$ The schematic experimental setup comprises the 6 in. integrating sphere, He:Cd CW laser with $325 \mathrm{~nm}, 1$ kW Xe lamp, and monochromator with a photomultiplier tube. The thicknesses of the spin-coated organic layers were measured with an alpha-step surface profiler, P-10 (Tencor). The luminescence-voltage $(L-V)$ and current efficiencyvoltage characteristics of OLEDs were measured using a Keithley 236 source measurement unit and Minolta CS-1000 spectrometer. In order to investigate the details of the energetic barriers in the devices, ultraviolet photoelectron spectroscopy was used to obtain the HOMO levels. The LUMO levels were determined from the HOMO level and optical

TABLE II. Device code for the evaluation of the interfacial layer on the molecularly doped phosphorescence. All devices have the same hole blocking, electron transfer, and cathode layers (5 nm-BAlq/25 nm $\left.-\mathrm{Alq}_{3} / 1 \mathrm{~nm}-\mathrm{LiF} / 250 \mathrm{~nm}-\mathrm{Al}\right)$.

\begin{tabular}{|c|c|c|c|c|}
\hline Device code & $\begin{array}{c}\text { Hole injection } \\
\text { layer }\end{array}$ & $\begin{array}{l}\text { Hole transport } \\
\text { (interfacial) layer }\end{array}$ & $\begin{array}{l}\text { Light emitting } \\
\text { layer }\end{array}$ & Remark \\
\hline $4 \mathrm{~s}$ & PEDOT:PSS & $\cdots$ & CBP:PVK: $\operatorname{Ir}(\mathrm{ppy})_{3}$ & Spin-coated \\
\hline $7 \mathrm{~s}$ & PEDOT:PSS & BFEC & CBP:PVK: $\operatorname{Ir}(p p y)_{3}$ & light emitting layers \\
\hline $8 \mathrm{~s}$ & PEDOT:PSS & TFB & CBP:PVK: $\operatorname{Ir}(\mathrm{ppy})_{3}$ & \\
\hline $9 \mathrm{~s}$ & PEDOT:PSS & BFEC (rinsed) & $\mathrm{CBP}: \mathrm{PVK}: \operatorname{Ir}(\mathrm{ppy})_{3}$ & \\
\hline $10 \mathrm{~s}$ & PEDOT:PSS & TFB (rinsed) & CBP:PVK: $\operatorname{Ir}(\text { ppy })_{3}$ & \\
\hline $4 v$ & PEDOT:PSS & $\cdots$ & $\mathrm{CBP}: \operatorname{Ir}(\mathrm{ppy})_{3}$ & Thernally evaporated \\
\hline $7 v$ & PEDOT:PSS & BFEC & $\mathrm{CBP}: \operatorname{Ir}(\mathrm{ppy})_{3}$ & light emitting layers \\
\hline $8 v$ & PEDOT:PSS & TFB & $\mathrm{CBP}: \operatorname{Ir}(\mathrm{ppy})_{3}$ & \\
\hline$\# 9 \mathrm{v}$ & PEDOT:PSS & BFEC (rinsed) & $\mathrm{CBP}: \operatorname{Ir}(\mathrm{ppy})_{3}$ & \\
\hline $10 \mathrm{v}$ & PEDOT:PSS & TFB (rinsed) & $\mathrm{CBP}: \operatorname{Ir}(\mathrm{ppy})_{3}$ & \\
\hline
\end{tabular}




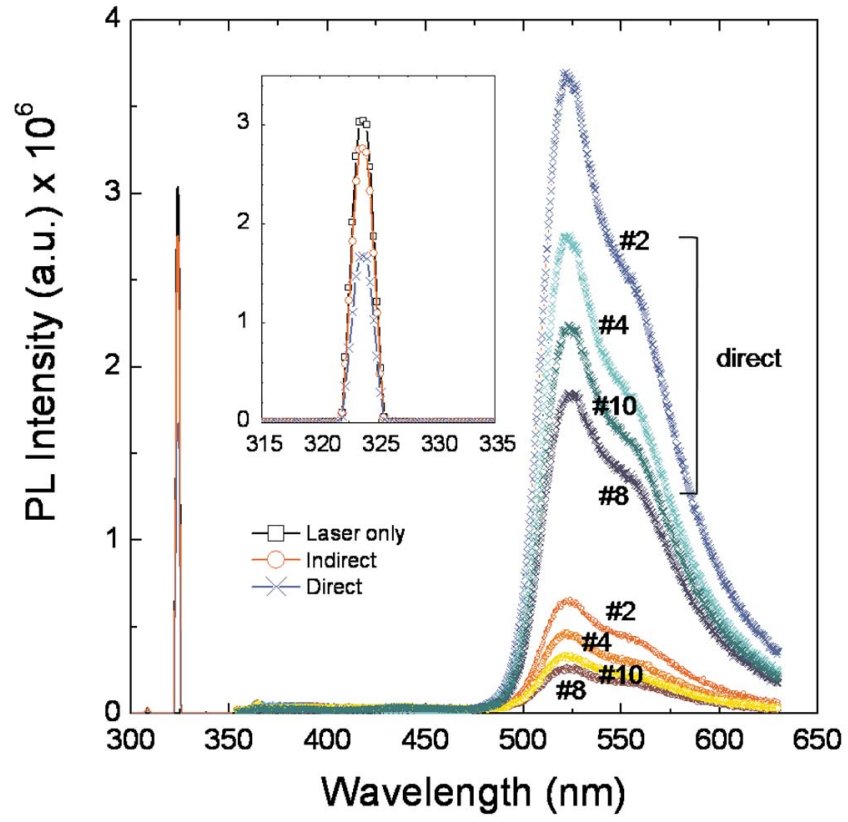

FIG. 2. (Color online) The complete spectra for the measurement of phosphorescent light emitting thin film of $46 \mathrm{~nm}$ thickness on bare quartz substrate (2), on $35 \mathrm{~nm}$ PEDOT:PSS film (4), on $16 \mathrm{~nm}$ TFB interfacial layer/ PEDOT:PSS (8), and on $11 \mathrm{~nm}$ TFB interfacial layer (rinsed)/PEDOT:PSS (10). The PL spectra were enlarged by a factor of 100 for a clear representation. The inset figure is with the enlarged axis of wavelength for laser irradiation peaks $(320-325 \mathrm{~nm})$.

energy gap values from the lower energy threshold of the electronic absorption spectra taken from organic films on the quartz substrates.

\section{RESULTS AND DISCUSSION}

\section{A. PLQY results of phosphorescent emitting multilayered thin film}

We have investigated the PLQY results that were obtained for the phosphorescent light emitting layer $\left[\mathrm{CBP}: \mathrm{PVK}: \operatorname{Ir}(\mathrm{ppy})_{3}\right]$ film and different cases for the emitting layer/interfacial layer. Figure 2 describes the entire spectra for the measurement of phosphorescent light emitting thin film [CBP:PVK: $\left.\operatorname{Ir}(\mathrm{ppy})_{3}\right]$ of $46 \mathrm{~nm}$ thickness spin coated onto a bare quartz plate, PEDOT:PSS, TFB (pristine), and TFB (rinsed). In the case of a single layer film of CBP:PVK: $\operatorname{Ir}(\text { ppy })_{3}(2$ in Table I), the area under each of the laser $(L)$ and PL $(P)$ profiles of spectra corresponds to $L_{(a)}$ $=6.74 \times 10^{6}, \quad L_{(b)}=6.12 \times 10^{6}, \quad L_{(c)}=3.7 \times 10^{6}, \quad P_{(b)}=4.76$ $\times 10^{7}$, and $P_{(c)}=2.49 \times 10^{6}$ in arbitrary units. Using the equations (see Fig. 1) defined by de Mello et al., ${ }^{18}$ the estimated total fraction of light absorbed by the film $(A)$ was 0.39 and $83.1 \%$ of PLQY $(\eta)$ was obtained. This result is somewhat lower than the $97 \%$ PLQY for a CBP: $\operatorname{Ir}(\mathrm{ppy})_{3}$ 2 wt $\%$ film, ${ }^{19}$ which is probably due to the aggregation of the $\operatorname{Ir}(\mathrm{ppy})_{3}$ in the PVK-containing film. At higher doping level, the value of $70 \%$ PLQY for a $\mathrm{CBP}: \operatorname{Ir}(\mathrm{ppy})_{3} 7 \mathrm{wt} \%$ film (without polymer) ${ }^{20}$ was also reported, implying aggregation-induced quenching. The other samples $(4,8$, and 10) are not single layers but multilayers of CBP:PVK: $\operatorname{Ir}(\mathrm{ppy})_{3}$ film on top of the interfacial layer/
PEDOT:PSS. Therefore, to estimate the PLQY $(\eta)$ changes in the emitting layer in various circumstances, the calculation of de Mello et al. ${ }^{18}$ need to be modified. Considerations for the effect of the absorption by the nonemissive layers placed between the emitting layer and the quartz substrate should be accounted for; otherwise the absorption value estimated will be higher, resulting in lower PLQY even though no quenching mechanism is present, which is obviously not true. When the fraction of absorbed light at each emitting layer and interfacial layer is separately expressed by $\mu_{(e)}$ and $\mu_{(i)}$ for the indirect irradiation and by $A_{(e)}$ and $A_{(i)}$ for the direct irradiation, the total absorption coefficient can be obtained from Eqs. (1)-(3). Here, the indirect, unabsorbed light intensity at (b) from reflection is $L_{(a)}\left(1-\mu_{(e)}\right)\left(1-\mu_{(i)}\right)$, and the intensity of unabsorbed light at $(\mathrm{c}),\left(L_{(c)}\right)$, can be defined by Eq. (2). It is assumed that there is PL only from the emitting layer and no interference of the emitted light in the multilayered structures:

$$
\begin{aligned}
& L_{(b)}=L_{(a)}\left(1-\mu_{(e)}\right)\left(1-\mu_{(i)}\right), \\
& L_{(c)}=L_{(a)}\left(1-A_{(e)}\right)\left(1-A_{(i)}\right)\left(1-\mu_{(e)}\right)\left(1-\mu_{(i)}\right), \\
& 1-\left(1-A_{(e)}\right)\left(1-A_{(i)}\right)=\left(1-\frac{L_{(c)}}{L_{(b)}}\right)=A^{*}, \\
& A^{*}=A_{(e)}+A_{(i)}-A_{(e)} A_{(i)} .
\end{aligned}
$$

The quantity $A^{*}$ is defined as the total absorption coefficient and can be simply calculated from the measurement of $L_{(b)}$ and $L_{(c)}$. Since the absorption of direct, collimated light will take place mainly in the light emitting layer, the contribution of the direct PL emission is $L_{(a)} A_{(e)}$. The sum of $L_{(c)}$ and $P_{(c)}$ is equal to the total contributions of the reflected and the scattered light $\left(L_{(b)}+P_{(b)}\right)$ and the collimated laser $\left(L_{(a)}\right)$. By the rearrangement of Eq. (5), modified equations for PLQY of the bilayer sample are given:

$$
\begin{aligned}
& L_{(c)}+P_{(c)}=\left(1-A^{*}\right)\left(L_{(b)}+P_{(b)}\right)+\eta L_{(a)} A_{(e)}, \\
& \eta=\frac{P_{(c)}-\left(1-A^{*}\right) P_{(b)}}{L_{(a)} A_{(e)}} .
\end{aligned}
$$

To obtain the PLQY $(\eta)$, the value of $A_{(e)}$ is extracted out from $A^{*}$ in Eq. (3) and the measured values of $L_{(b)}$ and $L_{(c)}$. Samples 3, 5, and 6 in Table I were accordingly prepared to measure $A_{(i)}$ at each case. Figure 2 (data for 4, 8, and 10) represents the spectral curves for the PL (direct and indirect) of the multilayered films. Compared to the result of the single phosphorescent emitting layer, decreases in both the direct and indirect PL intensities were observed for every multilayer sample first due to the absorption in the interfacial layer and then that in the PEDOT:PSS layer. The influence of the PEDOT:PSS on the PL intensity of molecularly doped triplet emitters was also quite conspicuous. The interaction of the triplet-emitter-doped polymeric layer with the adjacent PEDOT:PSS has been reported, showing the growth of a new emission band as a result of quenching during device operation. $^{21}$ Furthermore, the low triplet energy level of 
TABLE III. The excitation laser intensity $(L)$, emitted light intensity measured from the PLQY experiments in Fig. $1(P)$, calculated total absorption fraction $\left(A^{*}\right)$, and PLQY efficiencies $(\eta)$ for each sample.

\begin{tabular}{ccccccccc}
\hline \hline Sample code & $\begin{array}{c}L_{(a)} \\
\left(\times 10^{6}\right)\end{array}$ & $\begin{array}{c}L_{(b)} \\
\left(\times 10^{6}\right)\end{array}$ & $\begin{array}{c}L_{(c)} \\
\left(\times 10^{6}\right)\end{array}$ & $\begin{array}{c}P_{(b)} \\
\left(\times 10^{5}\right)\end{array}$ & $\begin{array}{c}P_{(c)} \\
\left(\times 10^{6}\right)\end{array}$ & $\begin{array}{c}A^{*} \\
\text { PLQY }(\eta)^{\mathrm{a}} \\
(\%)\end{array}$ & $\begin{array}{c}\text { PLQY }(\eta)^{\mathrm{b}} \\
(\%)\end{array}$ \\
\hline 1 & 6.74 & 6.58 & 6.71 & & & $\ldots$ & $\ldots$ & $\ldots$ \\
2 & 6.74 & 6.12 & 3.7 & 4.76 & 2.49 & 0.39 & 83.1 & 83.1 \\
3 & 6.74 & 6.6 & 6.54 & & & 0.01 & $\ldots$ & $\ldots$ \\
4 & 6.74 & 6.08 & 3.51 & 3.44 & 1.83 & 0.42 & 62.0 & 57.3 \\
5 & 6.74 & 6.34 & 4.75 & & & 0.25 & $\ldots$ & $\ldots$ \\
6 & 6.74 & 6.23 & 4.42 & & & 0.3 & $\ldots$ & $\ldots$ \\
7 & 6.74 & 5.99 & 2.67 & 2.05 & 1.11 & 0.55 & 38.7 & 27.3 \\
8 & 6.74 & 5.99 & 3.07 & 2.33 & 1.40 & 0.49 & 48.7 & 38.8 \\
9 & 6.74 & 5.98 & 2.87 & 2.19 & 1.31 & 0.52 & 45.8 & 34.4 \\
10 & 6.74 & 5.98 & 3.04 & 2.65 & 1.54 & 0.49 & 53.4 & 42.2 \\
\hline \hline
\end{tabular}

${ }^{\mathrm{a}} \mathrm{PLQY}(\eta)$ was calculated with the assumption that the thicknesses of emitting layers are all same throughout the devices. Additional absorption arising from the existence of PEDOT:PSS or interfacial layer was considered. ${ }^{\mathrm{b}} \mathrm{PLQY}(\eta)$ is calculated with the formula of de Mello et al. ${ }^{18}$ directly.

polyfluorene copolymers such as TFB $\left[2.2-2.3 \mathrm{eV},{ }^{17}\right.$ which is lower than the triplet energy level of $\left.\operatorname{Ir}(\mathrm{ppy})_{3}(\sim 2.4 \mathrm{eV})\right]$ is the origin of interfacial quenching of PL for the multilayer films of 8 and 10. Phosphorescent quenching in EL was also observed when the BFEC interfacial layer was used as one of the blend component of host material blends. ${ }^{22}$ Therefore, the phosphorescence quenching of the $\operatorname{Ir}(\mathrm{ppy})_{3}$ triplet emitter is obvious at least at the interfacial layer/emitting layer interface, showing the further reduction in both direct and indirect PL intensities. The PL intensities of the emitting layer on TFB yields an enhancement when the TFB interfacial layer was rinsed before fabricating the emitting layer (compare 10 to 8 ).

The results of the measurement on the intensity of the excitation light, the emitted light, the calculated total absorption coefficients, and the PLQY efficiencies for each sample are summarized in Table III. The inevitable assumption for these calculations is that the thickness of light emitting layers is the same for samples 2,4 , and $7-10$. Therefore, $A_{(e)}$ values of the samples are all equivalent to that of sample 2. In samples 9 and 10, the interfacial layers were rinsed with toluene, which eliminated the soluble part of the polymer layer. In order to find the absolute PL efficiency at the CBP:PVK: $\operatorname{Ir}(\mathrm{ppy})_{3}$ light emitting layer, we measured the intensity of absorption for the quartz substrate, PEDOT:PSS, and the interfacial layer materials to obtain $A_{(i)}$ values for references. Based on these conditions, the CBP:PVK: $\operatorname{Ir}(\mathrm{ppy})_{3}$ film on PEDOT:PSS showed a PLQY of $62.0 \%$, while the values for the interlayer-containing samples (7 and 8, emitting layer film on BFEC/PEDOT:PSS and TFB/PEDOT:PSS) undergoes further reductions down to $38.7 \%$ and $48.7 \%$, respectively. In the case of samples 9 and 10 (with rinsed interfacial layer), the PLQY showed increases up to $45.8 \%$ for BFEC and $53.4 \%$ for TFB interfacial layers (see PLQY in column 8 in Table III, considering the modified absorption coefficient influenced by the PEDOT:PSS or interfacial layers). For comparison, a direct application of the formula by de Mello et al. ${ }^{18}$ yields the lower PLQY efficiencies of the multilayered samples (PLQY in column 9 in Table III). Both for the samples with pristine and rinsed interfacial layers, the PL intensities of the emitting layer on TFB are larger than those for an emitting layer on BFEC. This can be attributed to the difference in the triplet quenching between TFB and BFEC. Moreover, enhancement in PLQY was observed for both BFEC and TFB after rinsing. We can deduce that the region of interfacial triplet quenching will be reduced in samples with annealed and rinsed interfacial layers. Outside of this quenching region, the PL emission is solely dependent on the Förster energy transfer between the host $(\mathrm{CBP}+\mathrm{PVK})$ and the dopant $\left[\operatorname{Ir}(\mathrm{ppy})_{3}\right]$, as reported in other host blends. ${ }^{23}$ Upon examining the direct and indirect PL emission spectra (Fig. 2), no change in the peak wavelength and shoulder emission was observed in spite of the variation in PL intensities at different cases of the interfacial layer structure.

\section{B. Characteristics of phosphorescent light emitting devices with interfacial layer}

The performances of devices with spin-coated light emitting layers of CBP:PVK: $\operatorname{Ir}(\mathrm{ppy})_{3}$ are given in Fig. 3; the results show the relationship between brightness versus applied voltage bias and luminous efficiency versus brightness. The brightness of the devices incorporating all the interfacial layers is higher through the whole range of bias voltage compared to the reference device (4s), showing a lower driving voltage behavior. In the case of devices with BFEC interfacial layer (7s, $25 \mathrm{~nm}$ BFEC; 9s, $15 \mathrm{~nm}$ BFEC rinsed), the luminance-current efficiency curves indicate that annealing and rinsing of the interfacial layer (which reduced the thickness from 25 to $15 \mathrm{~nm}$ ) result in a higher luminous efficiency. However, for the TFB interfacial layers, improvement in the current efficiency by rinsing is not observed. The reference device represents the highest luminous efficiency. However, the efficiency undergoes a rapid reduction at the high brightness (large current). Without an interfacial layer, the blended light emitting host material (CBP:PVK) seems to be characterized by injection limitation, with buildup of space charge likely to have arisen from the large HOMO level difference between the PEDOT:PSS (5.2 eV) and PVK $(5.8 \mathrm{eV})$. It should be also noted that the electron mobility of PVK is very poor compared to the hole mobility 

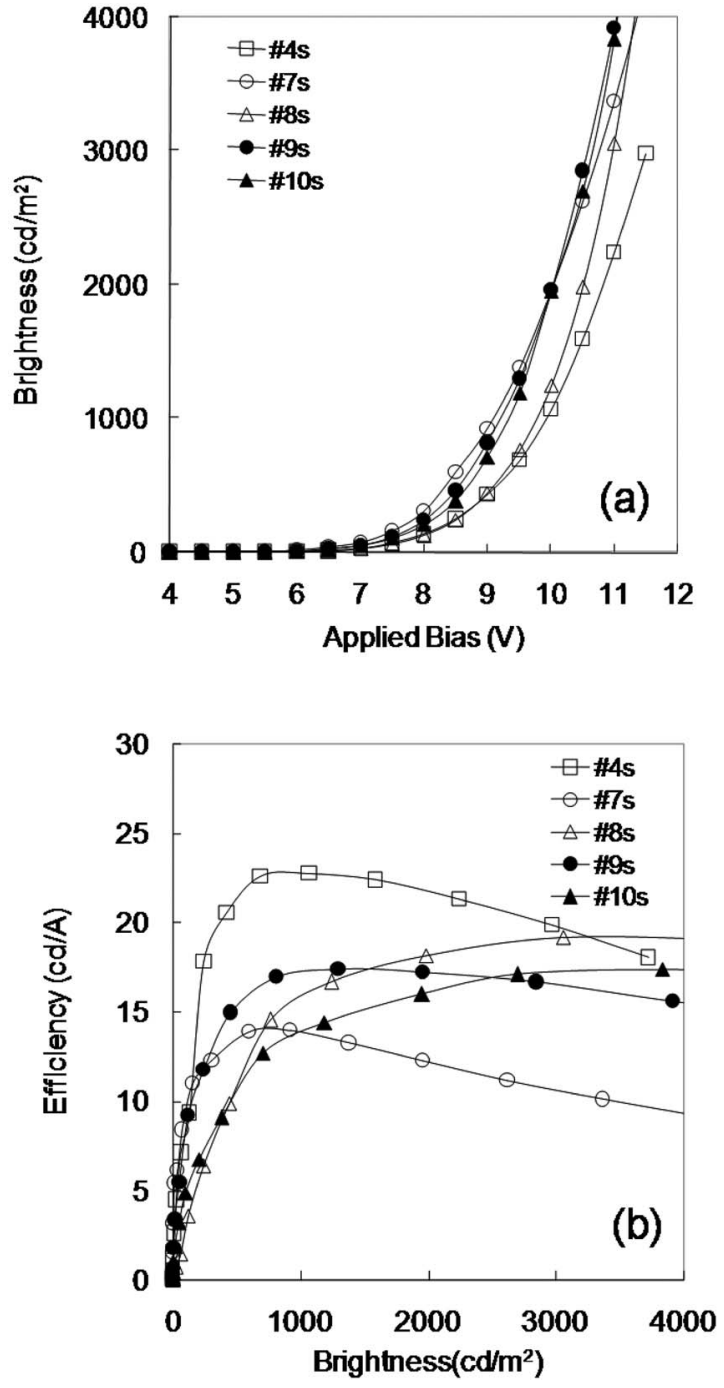

FIG. 3. The performance of devices with spin-coated light emitting layer of CBP:PVK: Ir(ppy) I $_{3}$ (a) brightness vs applied voltage bias and (b) luminous efficiency vs brightness behavior. Device codes (4s and 7-10s, shown in Table II) correspond to the multilayered specimen for PLQY with sample codes 4 and $7-10$, respectively.

$\left(10^{-5} \mathrm{~cm}^{2} \mathrm{~V}^{-1} \mathrm{~s}^{-1}\right),{ }^{24}$ implying the poor charge balance. Moreover, compared to the CBP host, the mobility of the CBP:PVK will be reduced due to the trapping by PVK. By a direct recombination mechanism at the dopant sites, a large portion of holes is trapped at the $\operatorname{Ir}(\mathrm{ppy})_{3}$ dopant HOMO. We can expect that luminous quenching at the PEDOT:PSS interface and imbalanced charge in device $4 \mathrm{~s}$ are responsible for lower brightness-voltage data and rapid drop of efficiency-luminance curve. ${ }^{21}$

Considering the HOMO energy level of the interfacial layers, the cascade hole injection into the emitting layer by the presence of the interfacial layer can explain the enhancement in the brightness by the matching of the HOMO level for the efficient hole injection. Exciton will be formed directly on $\operatorname{Ir}(\mathrm{ppy})_{3}$ from holes injected from the HOMO of BFEC $(5.43 \mathrm{eV})$ or the TFB $(5.45 \mathrm{eV})$ interfacial layer and from electrons primarily transported from the CBP LUMO. At the small HOMO level offset, a direct hole injection into the HOMO of the phosphorescent dopant has also been reported elsewhere. ${ }^{12}$ However, phosphorescent quenching at the BFEC/light emitting layer or TFB/light emitting layer interface will also affect the energy transfer efficiency toward the dopant $\left(\operatorname{Ir}(\mathrm{ppy})_{3}\right)$ while at the same time light emission by charge trapping mechanism is present. Therefore, a reduction in energy transfer efficiency with interfacial phosphorescent quenching competes with the improved charge injection efficiency by the cascade hole injection. Such a facilitated hole injection with interfacial layers will shift the recombination zone to the cathode,${ }^{11}$ causing the enhancement in brightness.

Yang et al. ${ }^{12}$ proposed that the formation of the insoluble interfacial layer on top of PEDOT:PSS is due to the binding of polymeric chains on the acidic surfaces upon thermal annealing. Therefore, the thickness of the insoluble interfacial layer will be dependent on the original thickness of the interfacial layer and physical/chemical interaction between the polymer and the PSS. The soluble portion of the BFEC interfacial layer seems to be rinsed out after annealing (reducing the thickness from 25 to $15 \mathrm{~nm}$ upon washing with toluene), while the thickness of TFB (originally $16 \mathrm{~nm}$ ) was almost unchanged during the annealing and rinsing processes. The soluble amount of BFEC layer might be "doped again" with CBP:PVK: $\operatorname{Ir}(\mathrm{ppy})_{3}$ emitting layer, leading to a further reduction in efficiency by triplet quenching [see Fig. 3(b) (sample 7s)]. The device with rinsed BFEC layer (9s) shows further increase in efficiency and brightness. Comparing the correspondingly layered samples ( 7 and 9 in Table III), we can observe the significant enhancement in PLQY efficiency by the reduction in bulk and interfacial quenchings.

Characteristics of devices with CBP: $\operatorname{Ir}(\mathrm{ppy})_{3}$ evaporated emitters $(4 \mathrm{v}$ and $7 \mathrm{v}-10 \mathrm{v}$ in Table II, which corresponds to the solution-processed devices of $4 \mathrm{~s}$ and $7 \mathrm{~s}-10 \mathrm{~s}$ ), are shown in Fig. 4. Quite differently from device $4 \mathrm{~s}$ (soluble emitter on PEDOT:PSS), the $I-V$ characteristics of thermally evaporated device of CBP: $\operatorname{Ir}(\mathrm{ppy})_{3}$ on PEDOT:PSS (4v) shows the highest brightness at the lower voltage bias (in this case PVK is not included as host). However, a reduction in brightness occurs at higher biases $(>10 \mathrm{~V}$, not shown in the figure) possibly due to lack of charge carrier balance. The data for devices $7 \mathrm{v}-10 \mathrm{v}$ in Fig. 4 probe the effectiveness of rinsing of the interfacial layers (BFEC and TFB) for thermally evaporated light emitting layer. The figure shows clear evidence of lower voltage behavior and enhanced current efficiency when the rinsing is performed [see the filled symbols in Figs. 4(a) and 4(b)].

In Fig. 5(a), the comparison of the EL spectrum at spincoated emitter [CBP:PVK: $\left.\operatorname{Ir}(\mathrm{ppy})_{3}, 4 \mathrm{~s}\right]$ and vacuumdeposited emitter [CBP: $\operatorname{Ir}(\mathrm{ppy})_{3}, 4 \mathrm{v}$ ] devices is given (without interfacial layer). Device $4 \mathrm{~s}$ shows the wavelength at the maximum peak $\left(l_{\max }\right)$ of $524 \mathrm{~nm}$, which is slightly redshifted compared to the result of $4 \mathrm{v}, \mathrm{CBP}: \operatorname{Ir}(\mathrm{ppy})_{3}$ film $\left(l_{\max }\right.$ $=512 \mathrm{~nm}$, also seen in another reference $\left.{ }^{19}\right)$. Additional hole trapping at PVK as well as thicker CBP:PVK: $\operatorname{Ir}(\text { ppy })_{3}$ emitter film [46 nm, compare to $30 \mathrm{~nm}$ CBP: $\operatorname{Ir}(\mathrm{ppy})_{3}$ film] might explain the change in the recombination zone and spectral behavior. The role of the interfacial layer on the EL spectral characteristics of devices is investigated for solutionprocessed emitters [Fig. 5(b)] and for vacuum-deposited 

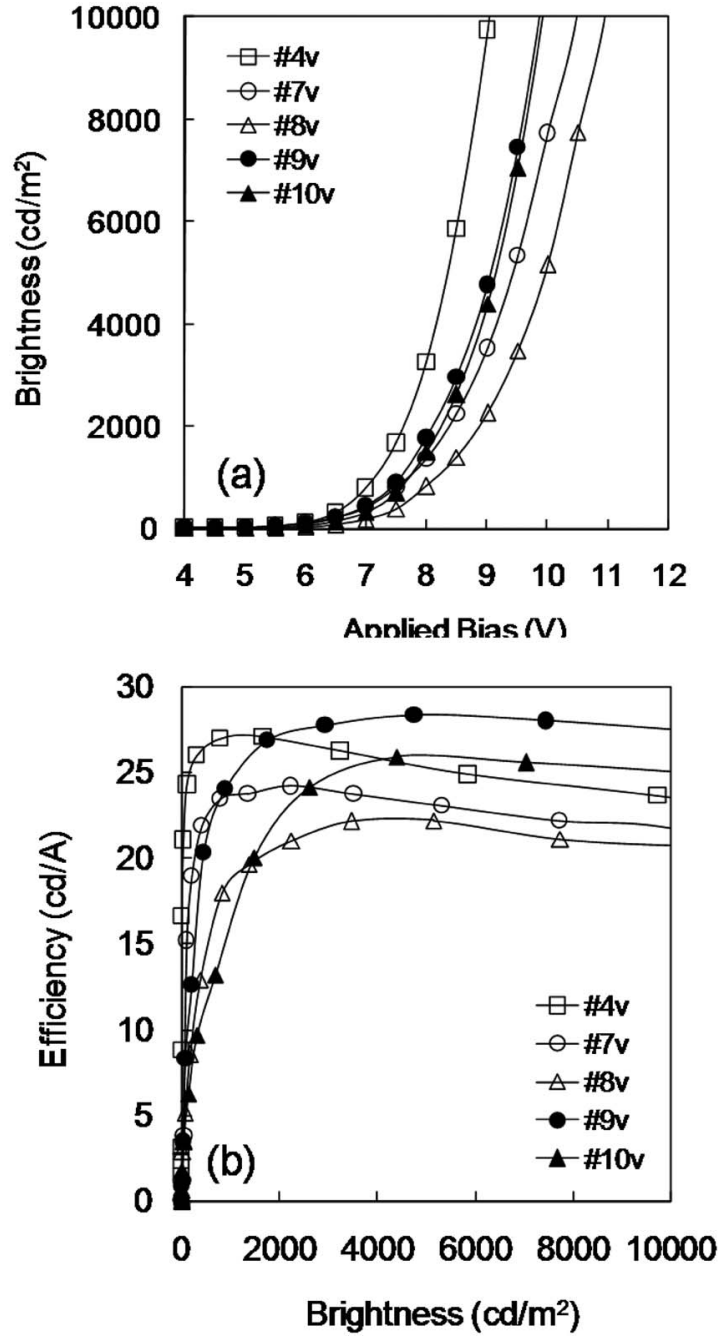

FIG. 4. The performance of devices with vacuum-deposited emitting layer of CBP: $\operatorname{Ir}(\mathrm{ppy})_{3}$ : (a) brightness vs applied voltage bias and (b) luminous efficiency vs brightness behavior. Device codes $(4 v$ and $7 v-10 v)$ are specified in Table II.

emitters [Fig. 5(c)]. Generally, devices with interfacial layer show a shoulder, a transition to the first vibronic level of the electronic ground state. In device 7s (pristine BFEC interfacial layer), the trace of the short-wavelength shoulder is observed (440-480 $\mathrm{nm}$ ), which might be attributed to the BFEC:PVK exciplex emission (from holes on BFEC and electrons from PVK). Such an emission is fairly reduced at a device with a rinsed, thin interfacial layer $(9 \mathrm{~s})$. The EL spectra of the devices with TFB [7s and 9s in Fig. 5(b)] do not show the noticeable short-wavelength shoulder emission compared to the reference (4s), which represents less exciplex formation. Since a change in the thickness of the TFB interfacial layer was barely noticed due to the rinsing process, the addition of a soluble TFB portion in the emitting layer will be negligible. Regardless of the thickness of the interfacial layer, the overall PLQY efficiency of the TFB/ emitting layer film is higher than that of the BFEC/emitting layer, which implies less interfacial triplet quenching. The spectral change in the hypsochromic/bathochromic shift at the shoulder of green emission can be rather explained by the shift in the recombination zone, which induces the difference in the outcoupling behavior.
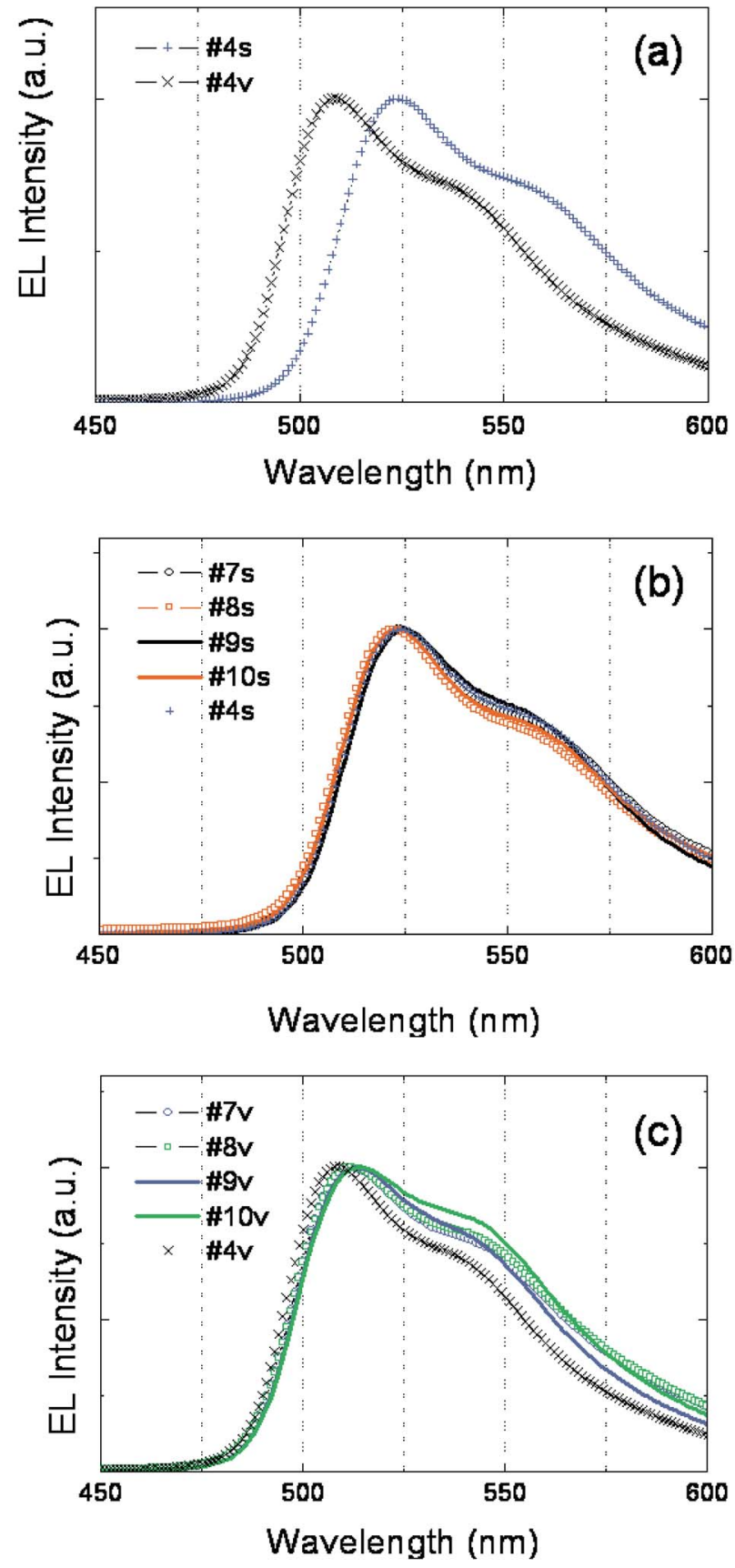

FIG. 5. (Color online) (a) EL spectral characteristics of devices without interfacial layer; comparison of spin-coated light emitting layer of CBP:PVK: $\operatorname{Ir}(\mathrm{ppy})_{3}(4 \mathrm{~s})$ and vacuum-deposited $(4 \mathrm{v})$. (b) Devices of spincoated light emitting layer of CBP:PVK: $\operatorname{Ir}(\mathrm{ppy})_{3}$ layer with interfacial layers (4s and 7s-10s). (c) Devices of vacuum-deposited light emitting layer of CBP: $\operatorname{Ir}(\text { ppy })_{3}$ layer with interfacial layers $(4 \mathrm{v}$ and $7 \mathrm{v}-10 \mathrm{v})$.

Figure 5(c) illustrates the normalized EL spectra of the devices with thermally evaporated light emitters. The entire device with interfacial layers $(7 \mathrm{v}-10 \mathrm{v})$ shows a $470-650 \mathrm{~nm}$ phosphorescence band of the CBP: $\operatorname{Ir}(\mathrm{ppy})_{3}$ film [with peak $l_{\max }=512 \mathrm{~nm}$, same as the PL peak of CBP: $\operatorname{Ir}(\text { ppy })_{3}$, and shoulder emission at 540-550 nm]. Compared to the reference device $(4 \mathrm{v})$, we could observe a slight bathochromic shift in $l_{\max }$ and the increase in the green shoulder emission at $540-550 \mathrm{~nm}$ for devices with interfacial layers $(7 \mathrm{v}-10 \mathrm{v})$. Unlike the spin-coated CBP:PVK:Ir(ppy $)_{3}$ emitter, shortwavelength shoulder by exciplex was not observed regard- 
less of the thickness of the interfacial layer and implementation of the rinsing process, which can be explained by the absence of PVK. The intensity in the shoulder emission at 540-550 nm, possibly vibronic transition, might result in the increase in luminous efficiency. However, at the same time, this shoulder emission, induced by the shift in the recombination zone (outcoupling effect), can influence the color purity of green emission. In order to describe this relationship thoroughly, details of charge trapping characteristics, energy transfer efficiency, and interactions between the interfacial layer and the $\operatorname{Ir}(\mathrm{ppy})_{3}$ emitter should be investigated further.

\section{CONCLUSION}

We have investigated the PLQY of spin-coated phosphorescent emitting materials on polyfluorene-based interfacial layers using integrated sphere measurements with excitation via a $325 \mathrm{~nm}$ laser. Regardless of the thickness and type of low triplet energy interfacial layers, PLQY results exhibited a reduction in yield by PL quenching, which shows even greater reduction in PLQY compared to the phosphorescent emitter on PEDOT:PSS. Based on the condition of the same thickness of emitting layers and total absorption coefficient considering the interfacial layer, the compensation for PLQY values for the multilayered samples was performed, yielding generally lower efficiency than that in the case of emittinglayer-only sample. The role of interfacial layers on the EL behavior was investigated with the analysis of the efficiency, brightness, and spectral behavior, which could be partially explained by the vibronic transition, interfacial exciplex, and shift in the recombination region. These factors are dependent on the carrier mobility, charge trapping, and energy transfer between the components of host, guest, and interfacial layers. Although these interfacial layers can prevent the triplet quenching from PEDOT:PSS, low triplet energy compared to $\operatorname{Ir}(\mathrm{ppy})_{3}$ induces the reduction in the luminous efficiency. However, improved hole injection and a high LUMO level (barrier for electron overflow) can define the balanced carrier recombination zone and hence improve the efficiencies at higher brightness. Alternative selection of the crosslinkable hole transport layers with higher triplet energy level and precisely controlled thickness will be beneficial for improving the solution-processable phosphorescent devices, since the effect of interfacial quenching (by the low triplet energy of most interfacial layer materials) would be less significant. However, advantages of the interfacial layer methods such as the easy process will be still useful for large area solution-processed devices when the underlying mechanism becomes clear.

Generally, the PLQY values at different interfacial layer conditions are in good accordance with the EL behavior, showing that devices with annealed, rinsed, and thin interfa- cial layers yield higher efficiency behavior. The use of BFEC and TFB for interfacial layer materials in phosphorescent devices is beneficial in terms of better charge injection and shift in recombination zone to cathode. Therefore, in order to obtain highly efficient and charge balanced phosphorescent devices with solution-processed emitters, the design of polymer-type interfacial layer materials with higher triplet energy level is strongly required while maintaining the other advantages such as high molecular weight, uniformity at surface, large carrier mobility/LUMO level, and stability at high temperatures.

\section{ACKNOWLEDGMENTS}

This research was supported by the Seoul R\&BD support program (CR070048) and "SystemIC2010" project, Ministry of Knowledge Economy, Korea.

${ }^{1}$ M. A. Baldo, S. Ramansky, P. E. Burrows, M. E. Thomson, and S. R. Forrest, Appl. Phys. Lett. 75, 4 (1999).

${ }^{2}$ C. Adachi, M. A. Baldo, M. E. Thomson, and S. R. Forrest, J. Appl. Phys. 90, 5048 (2001).

${ }^{3}$ V. Cleave, G. Yahioglu, P. Le Barny, R. H. Friend, and N. Tessler, Adv. Mater. (Weinheim, Ger.) 11, 285 (1999).

${ }^{4}$ C.-L. Lee, K. B. Lee, and J.-J. Kim, Appl. Phys. Lett. 77, 2280 (2000).

${ }^{5}$ M.-J. Yang and T. Tsutsui, Jpn. J. Appl. Phys., Part 2 39, L828 (2000).

${ }^{6}$ X. H. Yang and D. Neher, Appl. Phys. Lett. 84, 2476 (2004).

${ }^{7}$ M. Suzuki, S. Tokito, F. Sato, T. Igarashi, K. Kondo, T. Koyama, and T. Yamaguchi, Appl. Phys. Lett. 86, 103507 (2005).

${ }^{8}$ B. D. Chin, M. C. Suh, M.-H. Kim, S. T. Lee, H. D. Kim, and H. K. Chung, Appl. Phys. Lett. 86, 133505 (2005).

${ }^{9}$ B. D. Chin and C. Lee, Adv. Mater. (Weinheim, Ger.) 19, 2061 (2007).

${ }^{10}$ S. H. Kim, J. Jang, and J. Y. Lee, Appl. Phys. Lett. 90, 203511 (2007).

${ }^{11}$ S. A. Choulis, V.-E. Choong, M. K. Mathai, and F. So, Appl. Phys. Lett. 87, 113503 (2005).

${ }^{12}$ X. H. Yang, F. Jaiser, B. Stiller, D. Neher, F. Galbrecht, and U. Scherf, Adv. Funct. Mater. 16, 2156 (2006).

${ }^{13}$ N. Rehmann, D. Hertel, K. Meerholz, H. Becker, and S. Heun, Appl. Phys. Lett. 91, 103507 (2007).

${ }^{14}$ N. Rehmann, C. Ulbricht, A. Köhnen, P. Zacharias, M. C. Gather, D. Hertel, E. Holder, K. Meerholz, and U. S. Schubert, Adv. Mater. (Weinheim, Ger.) 20, 129 (2008).

${ }^{15}$ J. Kim, R. H. Friend, I. Grizzi, and J. H. Burroughes, Appl. Phys. Lett. 87, 023506 (2005).

${ }^{16}$ H. Yan, P. Lee, N. R. Armstrong, A. Graham, G. A. Evmenenko, P. Dutta, and T. J. Marks, J. Am. Chem. Soc. 127, 3172 (2005).

${ }^{17}$ D. Hertel, Y. V. Romanovskii, B. Schweitzer, U. Scherf, and H. Bassler, Macromol. Symp. 175, 141 (2001).

${ }^{18}$ J. C. de Mello, H. F. Wittmann, and R. H. Friend, Adv. Mater. (Weinheim, Ger.) 9, 230 (1997).

${ }^{19}$ Y. Kawamura, H. Sasabe, and C. Adachi, Jpn. J. Appl. Phys., Part 1 43, 7729 (2004).

${ }^{20}$ E. B. Namdas, A. Ruseckas, I. D. W. Samuel, S.-C. Lo, and P. L. Burn, J. Phys. Chem. B 108, 1570 (2004).

${ }^{21}$ A. van Dijken, A. Perro, E. A. Meulenkamp, and K. Brunner, Org. Electron. 4, 131 (2003).

${ }^{22}$ M.-H. Kim, M. C. Suh, J. H. Kwon, and B. D. Chin, Thin Solid Films 515, 4011 (2007).

${ }^{23}$ X. Gong, J. C. Ostrowski, D. Moses, G. C. Bazan, and A. J. Heeger, Adv. Funct. Mater. 13, 439 (2003).

${ }^{24}$ D. M. Pai, J. F. Yanus, and M. Stolka, J. Phys. Chem. 88, 4714 (1984). 